\title{
An approach to classifying human resources constraints to attaining health-related Millennium Development Goals Kaspar Wyss*
}

\author{
Address: Swiss Centre for International Health, Swiss Tropical Institute, Basel, Switzerland \\ Email: Kaspar Wyss* - kaspar.wyss@unibas.ch \\ * Corresponding author
}

Published: 06 July 2004

Human Resources for Health 2004, 2:I I doi:10.1 I86/1478-449|-2-II
Received: 23 December 2003

Accepted: 06 July 2004

This article is available from: http://www.human-resources-health.com/content/2/I/I I

(C) 2004 Wyss; licensee BioMed Central Ltd. This is an Open Access article: verbatim copying and redistribution of this article are permitted in all media for any purpose, provided this notice is preserved along with the article's original URL.

\begin{abstract}
Background: For any wide-ranging effort to scale up health-related priority interventions, human resources for health $(\mathrm{HRH})$ are likely to be a key to success. This study explores constraints related to human resources in the health sector for achieving the Millennium Development Goals (MDGs) in low-income countries.
\end{abstract}

Methods and framework: The analysis drew on information from a variety of publicly-available sources and principally on data presented in published papers in peer-reviewed journals. For classifying $\mathrm{HRH}$ constraints an analytical framework was used that considers constraints at five levels: individual characteristics, the health service delivery level, the health sector level, training capacities and the sociopolitical and economic context of a country.

Results and discussion: At individual level, the decision to enter, remain and serve in the health sector workforce is influenced by a series of social, economic, cultural and gender-related determinants. For example, to cover the health needs of the poorest it is necessary to employ personnel with specific social, ethnic and cultural characteristics. At health-service level, the commitment of health staff is determined by a number of organizational and management factors. The workplace environment has a great impact not only on health worker performance, but also on the comprehensiveness and efficiency of health service delivery. At health-sector level, the use of monetary and nonmonetary incentives is of crucial importance for having the accurate skill mix at the appropriate place. Scaling up of priority interventions is likely to require significant investments in initial and continuous training. Given the lead time required to produce new health workers, such investments must occur in the early phases of scaling up. At the same time coherent national $\mathrm{HRH}$ policies are required for giving direction on $\mathrm{HRH}$ development and linking $\mathrm{HRH}$ into health-sector reform issues, the scaling-up of priority interventions, poverty reduction strategies, and training approaches. Multisectoral collaboration and the sociopolitical and economic context of a country determine health sector workforce development and potential emigration.

Conclusions: Key determinants of success for achieving international development goals are closely related to human-resource development.

\section{Background}

In 2000, world leaders of low-, middle-, and high-income countries committed themselves to combating poverty, hunger, disease, illiteracy, environmental degradation 
and discrimination against women. Subsequently eight Millennium Development Goals (MDGs) were formulated, among them four related to the health of the poor. These targets imply the necessity to "eradicate extreme poverty and hunger, reduce child mortality, improve maternal health, combat HIV/AIDS, malaria and other diseases" [1] and to significantly improve coverage of the population and especially of the poor with priority interventions. Today in many countries only a minority of the population can benefit from health-related interventions; in most situations the poor have extremely limited access to services.

Over the last years, a series of concrete actions has emerged to improve the health of the poor, among them the Roll Back Malaria and Stop-TB partnerships, the Global Alliance for Vaccine and Immunization (GAVI) to protect health and save children's lives through the widespread use of vaccines, the Global Fund to Fight AIDS, Tuberculosis and Malaria (GFATM) and the recently launched " 3 by 5 " plan of the World Health Organization to rapidly expand access to AIDS treatment.

A number of challenges must be overcome in order for the additional resources to be invested effectively and efficiently $[2,3]$. For any large-scale effort to scale up priority intervention coverage of the population, human resources for health (HRH) will be a key to success. HRH heavily influence the effective and efficient delivery of services. $\mathrm{HRH}$ also determine in an important way absorptive capacities of supplementary resources to health systems in low- and middle-income countries. Thus, this study aims to explore constraints related to human resources in the health sector for achieving the MDGs in low-income countries. More precisely, the objective is to provide an analytical framework for identifying countries that may face HRH constraints in achieving the MDGs and to allow countries to determine their situation with regard to the intensiveness of HRH-related constraints.

\section{Methods and conceptual framework}

The analysis drew on information from a variety of publicly-available sources and principally on data presented in published papers in peer-reviewed journals.

Possible constraints related to the development of human resources in the context of scaling up health-related interventions were reviewed and discussed using the framework of Hanson et al. [3]. This framework was adapted for HRH-relevant issues and two levels were modified: the "community and household level" was changed to "individual characteristics" and "public policies cutting across sectors" was specifically tailored to "training capacities". Consequently, the range and intensity of HRH-related constraints at five levels were considered: individual char- acteristics, the health service delivery level, the health sector level, training capacities and the sociopolitical and economic context of a country (Table 1).

\section{Results and discussion Individual characteristics}

The scaling-up of priority interventions may require new personnel to be trained. The decision to enter, remain and serve in the health-sector workforce is influenced by the person's cultural, social and economic background, ethnicity, age, gender, education, physical and mental wellbeing, and other circumstances. The reputation of the medical and public health field, professional expectations and career-advancement perspectives are among the determinants for the choice to join a medical or nursing school. In many countries business, law or other economic sectors offer better opportunities and may thus negatively affect a decision to enrol in medical training. Or, to work as a public health doctor is seen by many physicians as less attractive than to practice as a specialist.

Priority needs such as maternity-related conditions may require female personnel with midwifery skills in rural areas. It has been shown that midwives are less likely to work in rural areas and tend to be concentrated in cities [4]. As more women enter the health sector workforce, it will become increasingly important to identify feasible strategies that are able to address gender-related differences in terms of choices for different training options or workplaces. Often women cluster in specific professional categories and levels of the health system, have lower incomes than men, and exit the workforce earlier due to pregnancy and the raising of children.

The MDGs call for priority to be given to the poorest and most needy. In many situations these groups are underrepresented in or absent from the health-sector workforce. For example, it has been reported that a major reason for extremely low health-service access and coverage of nomadic communities in Niger is linguistic and cultural differences from the health personnel [5]. Similar problems are reported for minority groups such as the Roma in Eastern Europe or migrant labourers. In Ghana it has been shown that health workers perceive themselves to be of higher social status than the patients [6]. Thus, it is not only necessary to have the right skill mix at a given health service, but also to dispose of personnel with a specific social, ethnic, cultural and gender background.

HIV/AIDS and other diseases may strongly influence the size of the workforce and the number of newly trained and skilled health personnel may easily be outstripped by high attrition rates including premature death of health workers due to AIDS. Illness and absence from the workplace may reduce the performance of health staff. Conse- 
Table I: HRH-related constraints and possible variables to measure constraints

\begin{tabular}{|c|c|c|}
\hline Constraint & Possible indicator & Data availability and potential source \\
\hline \multicolumn{3}{|l|}{ Individual characteristics } \\
\hline Gender & $\begin{array}{l}\text { Proportion of women in the workforce by skill } \\
\text { level }\end{array}$ & MoH statistical data and/or workforce census \\
\hline Social class and ethnicity of staff & $\begin{array}{l}\text { Representation of health workers from } \\
\text { minority groups }\end{array}$ & MoH statistical data and/or workforce census \\
\hline Demand for medical training & Number of applicants per training position & Medical training institutions \\
\hline Disease & $\begin{array}{l}\text { HIVIAIDS prevalence rates among health } \\
\text { workers }\end{array}$ & MoH statistical data and/or surveys \\
\hline \multicolumn{3}{|l|}{ Health service level } \\
\hline Team building and interaction & Number of team meetings and supervisions & Survey \\
\hline $\begin{array}{l}\text { Surpluses, shortages and skill mix at health } \\
\text { service level }\end{array}$ & $\begin{array}{l}\text { Proportion of health staff working in correctly } \\
\text { staffed services }\end{array}$ & MoH statistical data and/or surveys \\
\hline Physical working environment & $\begin{array}{l}\text { Proportion of health staff working in correctly } \\
\text { equipped services }\end{array}$ & MoH statistical data and/or surveys \\
\hline \multicolumn{3}{|l|}{ Health sector level } \\
\hline Salary level and monetary incentives & Salary grids in absolute terms & MoH and/or MoF statistical data \\
\hline Performance management and productivity & $\begin{array}{l}\text { Existence of frameworks for managing the } \\
\text { collection and use of performance evidence } \\
\text { (including carrier plans) }\end{array}$ & MoH policy documents surveys on productivity \\
\hline Composition of workforce and skill mix & $\begin{array}{l}\text { Shortages or surpluses of staff in particular } \\
\text { occupations or professions / Appropriately } \\
\text { skilled workers for addressing priority diseases } \\
\text { (e.g. HIVIAIDS, malaria, TB) }\end{array}$ & MoH statistical data and/or workforce census \\
\hline Geographical imbalances & $\begin{array}{l}\text { Distribution of appropriately skilled workers } \\
\text { across regions }\end{array}$ & MoH statistical data and/or workforce census \\
\hline Retention policy & Existence of retention policy & MoH policy documents \\
\hline Health sector reform & $\begin{array}{l}\text { Improvements in performance and } \\
\text { responsiveness to adjust staff roles }\end{array}$ & Surveys \\
\hline HRH policy and planning & $\begin{array}{l}\text { Planning of future } \mathrm{HRH} \text { availability and } \\
\text { requirements }\end{array}$ & MoH policy documents \\
\hline \multicolumn{3}{|l|}{ Training capacities } \\
\hline Training & Number of trainees per skill level & Medical training institutions \\
\hline Retraining & Number of re-trainees per skill level & Continuous medical training institutions \\
\hline \multicolumn{3}{|l|}{$\begin{array}{l}\text { Socio-political and economic context of a } \\
\text { country }\end{array}$} \\
\hline Multisectoral approaches & $\begin{array}{l}\text { Quality of exchange among different interest } \\
\text { groups and ministries }\end{array}$ & $\begin{array}{l}\text { Policy documents and/or complementary } \\
\text { assessments }\end{array}$ \\
\hline Migration & Number of health staff migrating & MoH statistical data and/or workforce census \\
\hline Governance and overall policy framework & $\begin{array}{l}\text { Political stability, priority attached to social } \\
\text { sectors, decentralization, civil service rules, etc. }\end{array}$ & $\begin{array}{l}\text { Policy documents and/or complementary } \\
\text { assessments }\end{array}$ \\
\hline
\end{tabular}

quences are a reduction in the availability of health workers and an increase in the workload on the remaining health workers. Indeed, from southern Africa it is reported that HIV/AIDS has resulted in acute staffing shortages in social sectors; major concerns were expressed about losses in previous development gains and current development efforts through reduced staffing levels and lower productivity rates [7].

\section{Health service delivery level}

Improving performance and productivity of health workers can potentially reduce HRH requirements in the context of scaling up priority interventions. However, in many countries performance and productivity of health workers are low. In Cameroon, for example, it was observed that only about a quarter of the working time is used for the production of health services [8]; from India it is reported that health workers were regularly absent from their assigned positions [9].

The commitment of health staff is determined by a number of organizational and management factors. Health workers are motivated by a feeling of responsibility and technical and financial achievement, working in an environment of mutual reliance in which differences are dealt with in a team spirit. Often staff members have little dedication to their professional assignments. Procedures for staff assignment also affect motivation. The 
effects of these deficiencies are manifold: required working hours are not respected, certain types of activities such as outreach visits are not carried out or the quality of patient-provider dialogue is deficient. Another consequence is that health workers develop alternative strategies such as accepting informal payments in order to cope with unacceptable working conditions [10-12].

In many countries staff performance is not effectively monitored and evaluated. Assessment practices are unsatisfactory, quality standards are badly defined and little attention is paid to transparent processes and performance audits [13]. There is urgency to design and enforce effective performance management systems of health workers to address productivity gains.

An element for performance improvement may consist of offering health workers a decent physical working environment. In Pakistan it has been shown that motivation to work in rural areas is linked to the presence or absence of suitable health facilities [14].

Productivity, as well as scaling-up of priority interventions, may also be negatively affected by imbalances in the skill mix - the mix of grades and occupations within a given health service. Although there is limited evidence on appropriate skill mixes in the composition of health workers at a given health services [15], surpluses or shortages of personnel with specific skills are reported for many countries. In countries of Eastern Europe and the former Soviet Union, medical education is oriented towards specialization and higher prestige is associated with becoming a specialist. Subsequently hospitals are often overstaffed while community health services lack personnel. Additionally, the skill mix in a health service may be strongly skewed either to unskilled personnel (often at the level of remote primary care providers) or towards specialists (often in hospitals or urban health services).

These determinants have a great impact not only on health worker performance, but also on the comprehensiveness and efficiency of health service delivery. New health-sector initiatives must take into account appropriate skill mixes of priority interventions, thereby maximizing benefits [15]. For example, the scaling-up of antiretroviral treatment of people living with AIDS requires well-balanced numbers of personnel with clinical, nursing and counselling, laboratory and pharmaceutical skills.

\section{Health sector level}

Health-sector reform as well as organizational and management issues at the health-sector level influence performance and productivity [16]. Setting correct incentives in the health sector is of crucial importance for having the right skill mix at the right place, for addressing geographical imbalances in the distribution of HRH and more generally for improving performance and performance management. For example, career plans, salary levels, recruitment, appointment and retention procedures strongly affect where health workers practise and whether they stay in the health sector. It was pointed out that new forms of organizational support are required for performance management at policy level, thereby proposing a conceptual framework for managing the collection and use of performance evidence [17].

Salary level is strongly linked with motivation and retention [6]. In many countries salaries of the governmental health sector workforce are low, in both absolute and relative terms compared to the private sector. In Tajikistan, for example, the monthly pay of family physicians corresponds to around US $\$ 10$, while for covering basic needs at least a tenfold increase is necessary [18]. Parallel activities, such as working during the morning shift for a public provider and in the afternoon for a private one, is a common strategy to complement low salary levels.

In order to retain health staff at the workplace and in the health sector, it is necessary to consider salary increases when scaling up priority interventions. Since in many countries HRH already absorb an important part of sectoral budgets, a significant increase in the pay of health sector workers may prove difficult in terms of preferences and choices to be given to salary expenditures and in terms of political feasibility.

However, the experience of countries that have used monetary incentives to address motivation and imbalances in the geographical distribution of health workers indicates that nonmonetary incentives are as important [19]. In Thailand, the results of an increase in remuneration and the improvement of living conditions alone offered to those who work in rural areas could not reverse geographical imbalances $[20,21]$. Other factors such as proximity to the family, attending courses, opportunities for research and teaching also influence an individual's decision about where to work [4].

The size and composition of the workforce determines whether priority interventions can be delivered effectively and efficiently. Countries such as Ghana, Mauritania, the United Kingdom and Zimbabwe report deficiencies of personnel with specific skills $[4,6,22,23]$. Scaling-up of interventions requires staffing of health services with appropriate skill mixes. Regions with high HIV/AIDS prevalence are likely to rely on different skill-mix patterns than regions where acute respiratory infections in children or malaria are predominant. Thus, it is not enough to develop and implement staffing norms across a country; 
allowance must be made for variation based on the epidemiological distribution of priority diseases (e.g. climatic or urban-rural differences) as well as for evolution over time.

The scaling-up of priority interventions is intimately linked to ongoing reforms in the health sector. Decentralization, the promotion of private practice, new financing and payment schemes and hospital and/or pharmaceutical reforms are currently promoted in many countries as a means to improve performance and outcomes of national health care systems. The development of HRH needs to tie in to these reforms. From Colombia it is reported that a purchaser-provider split and the transformation of public hospitals into "autonomous state entities" produced some productivity gains [24].

Contracting work to the private sector is an instrument of rationalization and extension of services that offers an opportunity to overcome the scarcity of human resources in the public sector and problems related to the retention of staff in the public sector. However, this requires the regulation of the private sector, which is itself demanding of public sector capacity. Further, contractual approaches are not likely to be a major contributor to an increase in the health sector workforce, though they may help to addresses shortages in specific circumstances [25]. Various countries, such as Tanzania, report having personnel with nursing and/or clinical skills unemployed through retrenchment policies introduced in the governmental sector in the 1990s, who potentially can be contracted through the private sector.

Last but most importantly, coherent and well-formulated national HRH policies and strategies are required for giving direction on HRH development and on how HRH relate to health-sector reform issues (e.g. decentralization, public-private mix), the scaling-up of priority interventions, poverty-reduction strategies, and training approaches. In many countries the development of coherent HRH planning approaches is of low priority $[26,27]$. Recently it was pointed out that even countries such as Australia, France, Germany, Sweden and the United Kingdom have a partial approach to planning the health-sector workforce and that the relationships between different categories of health professions are ignored $[28,29]$. More specifically, nurse-workforce requirements for addressing disease patterns of the population are often neglected. There is need for a strategic vision of the current and future availability and requirements of HRH.

\section{Training capacities}

Scaling-up of priority interventions is likely to require significant investments in trainees and medical and nursing training schools [30]. Taking into account the time lag between enrolment in training institutions and employment at a given workplace, such investments have to be made in the early stages of scaling-up.

With regard to initial training, additional investments in education and training of health workers are a crucial component for the development of human resources and need to be an integral part of scaling-up priority interventions. Countries with centrally organized training institutions may need to regionalize training schools, such as in the case of Chad [31]. To have appropriately trained staff requires significant changes in medical and nursing curriculum, pedagogical methods and admission criteria. In many countries, the focus of medical training needs to shift from hospital to primary-care assignments. Further, administration and management skills and/or the training of district managers requires attention. More generally, training approaches must tie into national health policies and priorities and respond to required HRH skill patterns.

With regard to continuous education and in-service training, it is important not only to make available the funding for these activities but also to develop and implement corresponding policies to maintain and improve skills of health staff and to address motivation and performance, especially in rural areas.

Medical and nursing training often involves not only the ministry of health, but also the ministry of education. Unless all involved parties allocate high priority to the development of HRH, additional investments in training risk being unproductive. Further, the training of new health personnel depends not only on capacities of training institutions but also on the availability of potential students to be enrolled in medical schools. Over the last years, various countries faced considerable constraints on their educational systems that negatively affected output rates of the secondary schooling system. Thus, there is a relation between potential difficulties of the secondary schooling system and professional schools for medical training, and the former may constrain the latter from finding enough potential trainees.

\section{Sociopolitical and economic context of a country}

The sociopolitical and economic situation of a country largely determines human resource constraints for achieving the MDGs. Contextual characteristics include the historical, political, economic and social situation in which the state and its entities, communities and individuals can interact and operate. Factors such as governance and the overall policy framework, the degree of political stability, security, priority accorded to social sectors and accountability significantly influence whether and where health professionals practise. 
There is both a national and international component of the sociopolitical and economic context of a country. Emigration of medical professional illustrates this. Recruitment policies, immigration laws and regulations in better-off countries influence whether there is a demand for health professionals in high-income countries. On the other hand, living conditions in a lowincome country determine whether health staff is motivated to leave the country. With various high-income countries such as France, the UK and the USA having a high demand for health professionals trained outside their country, there is a growing concern that they absorb large numbers of health staff from low-income countries $[22,23,32]$. For example, it is reported that the USA is short of several hundred thousand nurses and that the high demand for medically trained staff is not likely to be reversed in the coming years. For the UK it has been shown that the number of overseas nurses entering has risen by $48 \%$ at the end of the 1990 s, most of them from countries such as the Philippines, South Africa and the West Indies $[33,34]$. For Ghana it is estimated that over $50 \%$ of locally-trained doctors are living and practising outside the country [6]. If the pull factors of migration to high-income countries and push factors in low-income countries cannot be simultaneously addressed, investments in medical and nursing training are likely to be in vain. One element is well-balanced and solidly elaborated national retention strategies.

In various African countries the size of the governmental workforce has eroded in the context of policy measures introduced under structural adjustment in the early 1990s that aimed at a retrenchment of the health workforce (for example, ceasing the automatic integration of new trainees). If these policy measures are not reversed, the scalingup of priority interventions will not be successful, as the number of newly integrated and skilled health personnel will be outweighed by attrition.

Multisectoral approaches and policies are required for effective and efficient HRH development. Unless healthsector development is not a recognized high priority of a country, it is not likely that there will be enough backing for the health sector to carry forward the extension of services. Political support to HRH development must be followed by budgetary support. However, the political and economic feasibility of increases in public expenditure may prove difficult, as other sectors may disagree with giving priority to the social sector(s). Further, various countries still are under considerable pressure from international organizations to pursue structural adjustment, with the consequence that allocation to the social sector cannot be increased.
Governance issues, such as political and administrative decentralization or civil service reform, shape the context in which health services function. Governance of a given country may change considerably within short periods and strongly influence HRH development and related constraints.

\section{Conclusions}

Debt-relief initiatives earmarked for the health and education sector as well as the commitment of the international community to achieve the MDGs offer a unique opportunity to strengthen health services in low-income countries. These initiatives put human-resource issues at the forefront, but need the corresponding leadership and strategic vision of government and decision-makers. Initiatives such as the MDGs, the Roll Back Malaria and Stop-TB partnerships, the Global Alliance for Vaccine and Immunization (GAVI) and the Global Fund to Fight AIDS, Tuberculosis and Malaria (GFATM) are based not only on the scaling-up of health-related interventions but require human resources to implement them.

There will be significant constraints to rapidly building up a health sector workforce able to implement priority interventions at high coverage levels. Hanson et al. [3] have presented a methodology for empirical analysis and country typology for analysing constraints. In this study, the identification of HRH-related constraints was made along five levels (individual characteristics, health service and health sector level, training capacities and sociopolitical and economic context of the country) and relied on a variety of data presented in published papers in peer-reviewed journals. Such an analytical framework may be used to classify countries and eventually to monitor and evaluate progress over time.

However, independent of a country classification along HRH-related constraints, the size and extent of the different constraints in the context of scaling-up priority interventions in low- and middle-income countries will vary. In broad terms, and with regard to individual characteristics of health workers, it is necessary to employ personnel with a specific social, ethnic, cultural and gender background for an effective and efficient delivery of priority interventions to the poorest and most disadvantaged.

At health-service level a number of organizational and management factors determine the dedication and productivity of health staff. At health-sector level, the use of monetary and non monetary incentives are of crucial significance for having the accurate skill mix at the appropriate place and for addressing geographical imbalances in the distribution of the health sector workforce. Unfortunately the role of incentives is currently largely ignored. 
Table 2: Estimated size of HRH-related constraints for typical low-income countries in Africa

\begin{tabular}{|c|c|c|}
\hline Level & Constraint & $\begin{array}{l}\text { Estimated size of the constraints in the context of } \\
\text { scaling-up in low- and middle-income countries }\end{array}$ \\
\hline \multicolumn{3}{|c|}{ Individual characteristics } \\
\hline & Gender & ++ \\
\hline & Social class and ethnicity of staff & +++ \\
\hline & Demand for medical training & + \\
\hline & Disease* & ++ \\
\hline \multicolumn{3}{|c|}{ Health service level } \\
\hline & Team building and interaction & ++ \\
\hline & $\begin{array}{l}\text { Surpluses, shortages and skill mix at health service } \\
\text { level }\end{array}$ & ++ \\
\hline & Physical working environment & + \\
\hline \multicolumn{3}{|c|}{ Health sector level } \\
\hline & Salary level and monetary incentives & ++ \\
\hline & Performance management and productivity & +++ \\
\hline & Composition of workforce and skill mix & ++ \\
\hline & Geographical imbalances & +++ \\
\hline & Retention policy & ++ \\
\hline & Health sector reform & ++ \\
\hline & $\mathrm{HRH}$ policy & +++ \\
\hline \multicolumn{3}{|c|}{ Training capacities } \\
\hline & Initial training & +++ \\
\hline & Re-training & +++ \\
\hline \multicolumn{3}{|c|}{ Sociopolitical and economic context of a country } \\
\hline & Multisectoral approaches & ++ \\
\hline & Migration & ++ \\
\hline & Governance and overall policy framework & +++ \\
\hline
\end{tabular}

* Heavily influenced by the epidemiological situation of HIVIAIDS for a given country $+++=$ very important; $++=$ important; $+=$ moderate

At the same time, coherent national HRH policies are required to better integrate planning across the professions, with special attention to skill mix and geographic imbalances. These policies should be conceived through participatory processes involving different stakeholder groups and need to give direction on HRH development and linking HRH into health-sector reform issues, the scaling-up of priority interventions, poverty reduction strategies, and training approaches. Key determinants of success are the long-term political commitment to HRH development and the integration of efforts with other social sectors such as education.

Finally, scaling up priority interventions is likely to require significant investments in initial and continuous training. Given the lead time required to produce new health workers, such investments must occur in the early phases of scaling-up.

In summary, the most important human resources-related challenges for a typical low-income country in sub-Saharan Africa are likely to include the following factors (Table 2):
- Addressing the proportional representation of staff with a distinct social, ethnic and gender background in the workforce

- Tackling geographical imbalances in the distribution of health sector workforce

- Improving performance management

- Extending qualitative and quantitative capacities of medical training institutions

- Conceiving and implementing national HRH policies

- Carrying forward good governance and a well conceived and balanced overall policy framework.

These factors are mutually connected and interrelated. As pointed out by Egger et al. [35], countries that successfully improve HRH problems are those "that 1) adjust the specific HRH strategies to meet the demands of their country's health sector reforms, the political/macroeconomic context, and government administrative policies; and 2) use policy-making processes that are consultative, "owned 
by the country", based on sound data, and supported by adequate human and financial resources".

\section{Competing interests}

None declared.

\section{Acknowledgements}

The author is grateful to Dr Mario Dal Poz and Dr Carmen Dolea of the World Health Organization for comments on an earlier draft of this paper. Financial support for this study was provided by the Department of Human Resources for Health, World Health Organization, as well as the Swiss National Science Foundation and the Swiss Agency for Development for Cooperation through Individual Project 4, "Health and well-being" of the "National Centre for Competence in Research (NCCR) North-South: Research Partnership for Mitigating Syndromes of Global Change".

\section{References}

I. United Nations: United Nations Millennium Development Goals (MDG). 2000 [http://www.un.org/millenniumgoals/]
. accessed: 15 May 2003

2. Mills $A$ : More funds for health: the challenge facing recipient countries. Bulletin of the World Health Organization 2002, 80: I 64- 165.

3. Hanson K, Ranson K, Oliveira-Cruz V, Mills A: Constraints to scaling up health interventions: a conceptual framework. Journal of International Development 2003, 15: I- I4.

4. Zurn P, Dal Poz M, Stilwell B, Adams O: Imbalances in the health workforce: briefing paper. Geneva: World Health Organization 2002 [http://www.who.int/hrh/documents/en/imbalances briefing.pdf]. accessed 25 February 2003

5. Loutan $L$ : Les problèmes de santé dans les zones nomades. In: La Santé en Pays Tropicaux Edited by: Rougement A, Brunet-Jailly J. Paris: Doin Editeurs; 1989:219-253.

6. Dovlo D, Nyonator F: Migration by graduates of the University of Ghana Medical School: a preliminary rapid appraisal. Human Resources for Health Development Journal 1999, 3:40-51.

7. Aitken JM, Kemp J: HIVIAIDS, equity and health sector personnel in southern Africa. Harare: EQUINET and OXFAM GB 2003. (EQUINET discussion paper No. 12)

8. Bryant $M$, Essomba RO: Measuring time utilization in rural health centres. Health Policy and Planning 1995, 10:415-42I.

9. Filmer $D$, Hammer J, Pritchett $L$ : Weak links in the chain: a prescription for health policy in poor countries. The World Bank Observer 2002, 17:47-66.

10. McPake B, Asiimwe D, Mwesigye F, Ofumbi M, Streefland P, Turinde A: Coping strategies of health workers in Uganda. In Providing Health Care under Adverse Conditions: Health Personnel Performance \& Individual Coping Strategies Edited by: Ferrinho P, Van Lerberghe W. Antwerp: ITG Press; 2000:131-150.

II. Van Lerberghe W, Conceicao C, Van Damme W, Ferrinho P: When staff is underpaid: dealing with the individual coping strategies of health personnel. Bulletin of the World Health Organization 2002, 80:58I-584.

12. Ensor T: Informal payments for health care in transition countries. Social Science and Medicine 2004, 58:237-246.

13. Miller Franco L, Bennett S, Kanfer R, Stubblebine P: Determinants and consequences of health worker motivation in hospitals in Jordan and Georgia. Social Science and Medicine 2004, 58:343-355.

14. Zaidi A: Why medical students will not practice in rural areas: evidence from a survey. Social Science and Medicine 1986, 22:527-533.

15. Buchan J, Dal Poz M: Skill mix in the health care workforce: reviewing the evidence. Bulletin of the World Health Organization 2002, 80:575-580.

16. Rigoli $F$, Dussault $G$ : The interface between health sector reform and human resources in health. Human Resources for Health 2003, I:9.

17. Hornby P, Perera HS: A development framework for promoting evidence-based policy action: drawing on experiences in Sri Lanka. International Journal of Health Planning and Management 2002, 17:165-83.
18. European Observatory on Health Care Systems: Tajikistan - Health Care Systems in Transition London: European Observatory on Health Care Systems; 2002.

19. Dielmann M, Viet Cuong P, Vu Anh L, Martineau T: Identifying factors for job motivation of rural health workers in north Viet Nam. Human Resources for Health 2003, I: 10.

20. Wibulpolprasert S, Pengpaiboon P: Integrated strategies to tackle the inequitable distribution of doctors in Thailand: four decades of experience. Human Resources for Health 2003, I:I2.

21. Nitayarumphong S, Srivanichakom S, Pongsupap Y: Strategies to respond to health manpower needs in rural Thailand. In Providing Health Care under Adverse Conditions: Health Personnel Performance \& Individual Coping Strategies. Studies in Health Services Organisation \& Policy 16 Edited by: Ferrinho P, Van Lerberghe W. Antwerp: ITG Press; 2002:53-70.

22. Bundred PE, Levitt C: Medical migration: Who are the real losers? Lancet 2000, 356:245-246.

23. Pang T, Langsang MA, Haines A: Brain drain and health professionals - a global problems needs global solutions. British Medical Journal 2002, 324:499-500.

24. McPake B, Yepes FJ, Lake S, Sanchez LH: Is the Colombian health system reform improving the performance of public hospitals in Bogota? Health Policy and Planning 2003, 18:182-194.

25. Palmer N, Mills A: Classical versus relational approaches to understanding controls on a contract with independent GPs in South Africa. Health Economics 2003, I 2: 1005-20.

26. Dussault G, Dubois C: Human resources for health policies: a critical component in health policies. Human Resources for Health 2003, I:I.

27. Buchan J: What difference does ("good") HRM make? Human Resources for Health 2004, 2:6.

28. Bloor K, Maynard A: Planning Human Resources in Health Care: Towards an Economic Approach. An International Comparative Review 2003 [http:/ /www.chrsf.ca]. Ottawa: Canadian Health Services Research Foundation accessed 20 May 2003

29. World Health Organization Regional Office for Africa, World Bank: Building Strategic Partnerships in Education and Health in Africa. Report of a Consultative Meeting on Improving Collaboration between Health Professionals, Governments, and Other Stake-Holders in Human Resources for Health Development Brazzaville: World Health Organization; 2002.

30. Adams O, Dussault G: Preface. In Towards a Global Health Workforce Strategy Volume 2I. Edited by: Ferrinho P, Dal Poz M. Antwerp: ITG Press; 2003:I-3.

31. Wyss K, Doumagoum MD, Callewaert B: Constraints to scalingup health related interventions: the case of Chad, Central Africa. Journal of International Development 2003, 15:87-100.

32. Farmer PE, Furin JJ, Katz JT: Global health equity. Lancet 2004, 363:1832.

33. Buchan J: Recruitment. Happy landings? Health Serv J 2000, 24:24-27.

34. Buchan J, Dovlo D: International Recruitment of Health Workers to the UK: A Report for DFID 2004 [http://www.dfidhealthrc.org/shared/pub lications/reports/int rec/exec-sum.pdf]. accessed 28 June 2004

35. Egger D, Lipson D, Adams O: Achieving the Right Balance: The Role of Policy-Making Processes in Managing Human Resources for Health Problems. Discussion Paper 2. WHO/EIP/OSD/00.2 Geneva: World Health Organization; 2000.

Publish with Biomed Central and every scientist can read your work free of charge

"BioMed Central will be the most significant development for disseminating the results of biomedical research in our lifetime. "

Sir Paul Nurse, Cancer Research UK

Your research papers will be:

- available free of charge to the entire biomedical community

- peer reviewed and published immediately upon acceptance

- cited in PubMed and archived on PubMed Central

- yours - you keep the copyright

Submit your manuscript here:

http://www.biomedcentral.com/info/publishing_adv.asp
BioMedcentral 